\title{
Analysis on the Current Situation of University Budgeting under the Guidance of Government
}

\author{
Ren Lanqing \\ Department of Economy and Management, Nanjing University of Science and Technology, District Xuanwu, \\ Nanjing, China \\ wshrlq@163.com
}

Keywords: budget management, budget making, public institution

\begin{abstract}
This research focuses on how the budget making of Chinese universities is carried out and affected. And for that there are certain organizational characteristics in the universities engaged in public service as public institutions, this paper studied the characteristics of budget management in universities. With those characteristics, the current situation of budget making in universities are researched. Furthermore, to achieve the national requirements that the budget making should be comprehensive, scientific and detailed, this paper found that some improvements should be made.
\end{abstract}

\section{Introduction}

Chinese university is a kind of public institutions, controlled by nation. Budget management is one of the methods used in the institutions. And budget making, as the first step of budget management, is fundamental part in it. In china, the new budget law was passed in 2014, further promoting the legalization of public finance budget. With the beginning of the departmental budget reform in 2000, the government has strictly managed the budgets of public institutions in the public finance system. The guidance of government plays an important role in the mechanism, process, time and content of budget making in universities, requesting the budget making to achieve the national requirements of being comprehensive, scientific and detailed. Under the background, this research will focus on how the budget making of Chinese universities is carried out and affected. Firstly, as universities engaged in public service as public institutions, with certain organizational characteristics. the budget management is different from that in companies. Combining these features, this paper will further study the current situation of budget making in universities in china and how to improve it.

\section{Characteristics of Budget Management in Universities}

Institutional attributes and business characteristics of universities lead to its inability to divorce budgeting from public finance, which causes that the management of institutions has some certain characteristics of the budget management.

\subsection{The Objective of Budget Management}

As public welfare institutions, the value of universities is to provide public goods and services for the community. Therefore, the ultimate goal of this kind of organization is to complete the duties assigned by the state. From this point, the budget management of institutions should also be more concerned about the efficiency and effectiveness of public service provided, to achieve the effective allocation of social resources. A large number of studies have confirmed that the budget management of the institution has its own particularity. Public institutions have a higher value in management target than enterprise, that is, in the procession of providing services and products, to ensure the effectiveness of the allocation of public resources.

\subsection{Unique Behaviour, Procedure and Control Mode}

Although the university is an independent organization, they are controlled more by the 
government than companies. Because the leadership of university is appointed by the government, the part of subordinate staff's recruitment requires approval of the competent authorities, and the main income resource is form national supporting. On the one hand, compared with the administrative institutions, China's universities, as a public institution, are of public nature, and their income sources and expenses are diversified. On the other hand, compared with the enterprise, due to the duty of providing social service, university has its own way of behaviour, procedure and control mode. In other words, the unique characteristics of universities lead to its unique budget management, with a high degree of research value in budget making.

\subsection{Higher Demand for Budget Management}

Due to the public attribute of its financial resources, a university is more concerned about how to improve the efficiency of public resources and funds, with the principle of openness, fairness and impartiality. Based on this feature, the universities are required higher quality of budget management, and also are paid close attention by scholars. They pointed out that the disclosure of budget information is to achieve the demand of accelerating the construction of democratic society, and is an effective measure to prevent corruption.

\section{Analysis of Budget Making}

According to the above analysis, the budget management of colleges and universities in China is peculiar, and its management style and organizational responsibility are very different from those of enterprises, highly supervised by the society. With these characteristics, the budget preparation of universities in our country is developing and improving, but there are some certain problems in existing mechanisms, methods and the participations. The concrete analysis is as follows:

\subsection{Budgeting Time}

Universities belong to public institutions, so it's essential for them to strictly abide by the regulations of national department budget. According to the regulations in Jiangsu Province, the budgeting for 2016 started in October 2015. And the arrangement in process and schedule of budget making is shown in Fig. 1. And according to the field survey, a supervisor from university in Jiangsu Province, in charge of the department budget, expects to start their own budgeting in advance in the preparation of 2018. The phenomenon shows that universities with diversified business structure and complicated economic structure lack of sufficient budget preparation time, rendering there isn't a detailed, comprehensive and scientific budgeting plan.

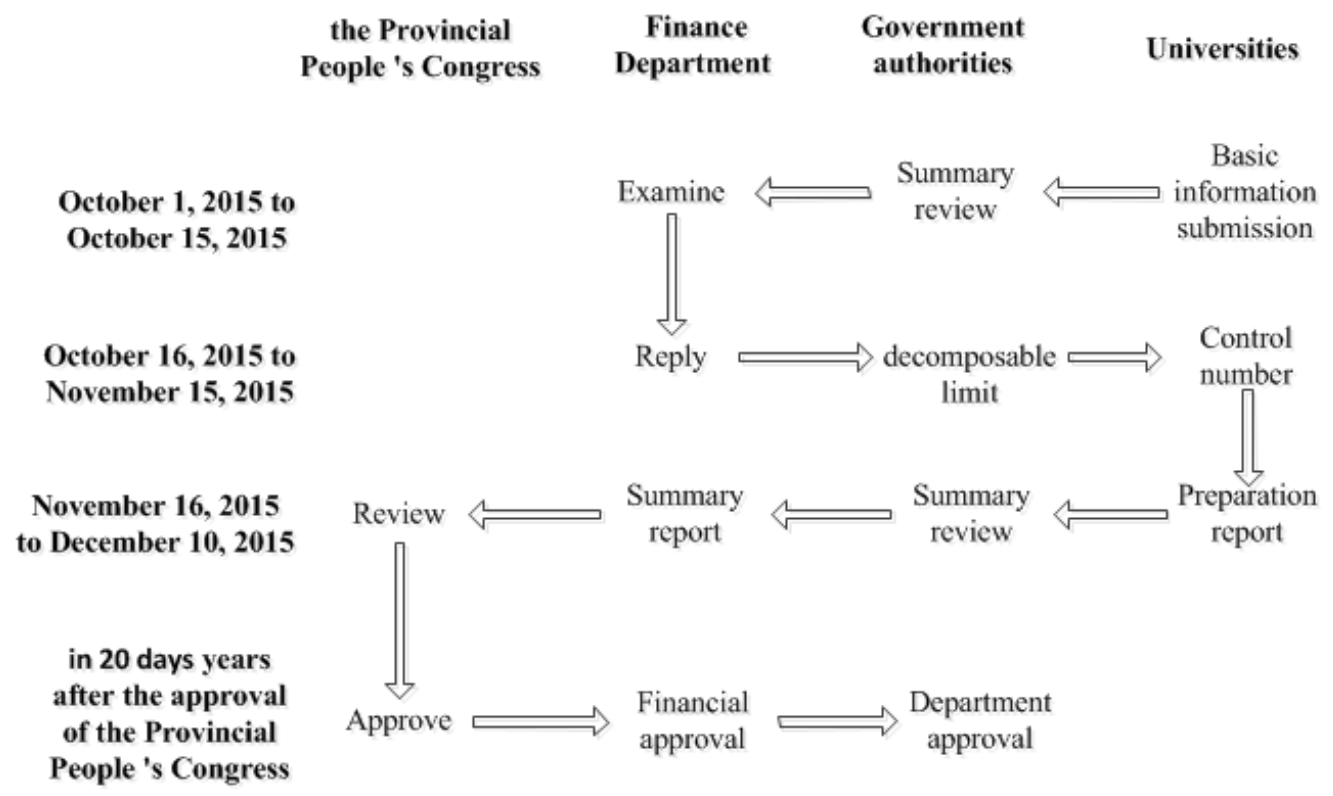

Figure 1 Flow Chart of 2016 Department Budget in Jiangsu Province 


\subsection{Professional Staff}

It is not hard in field survey to find that the staff who are responsible for the budgeting play an important role. Some of them would organize a meeting to convey the budgeting principles to his colleagues who submit information. And after the collection of basic information, this professional staff should be responsible for the final data audit and statistics. At the same time, the staff need to communicate with multiple parties for better resource allocation, including principals and heads of flat department. Therefore, the university's managers of budget making is bound to meet high professional requirements, including a full understanding of the contents of the budget declaration, an accurate judgment on the scientific nature of the budget declaration, and a reasonable allocation of budget funds.

\subsection{Budgeting method}

It can be seen that the accuracy of the budget submission data of each department will be affected by the judgment of its own supervisor. And the use of inaccurate data will have a poor impact on the budgeting results. For example, according to the relevant regulations of our institutions in the preparation of project expenditure, university should make the zero-based budgeting, a method of calculating the project from the beginning, rather than based on history data of previous budget execution. However, according to the survey, the method most of universities used is not the real zero-based budget. What they do is to reorder the importance of each project, and then arrange funds. And the new year's fund plan of a specific project still refers to past data, resulting that the responsible department in the preparation of the budget will reduce the consideration of future factors. The basis of the calculation is not accurate, will bring the ultimate allocation of funds great difficulties, failing to prepare a truly scientific and reasonable budgeting plan.

\section{Improvement}

The existence of the above problems is affected by the mechanism level, the technical level and the behavior level respectively. At the mechanism level, system of universities need to be further improved, laying the foundation for the perfection of budget preparation. At the technical level, the information and measurement methods in universities need to be improved for the efficiency and effectiveness of budgeting. What the analysis of behaviours level discusses is that the management of universities needs to pay more attention on budgeting, promoting the lower-level budget management to learn, and create their own budget culture in campus management.

\subsection{Mechanism}

The establishment of the mechanism is dependent on the scientific system. In the university management, the importance of the establishment of the system is self-evident, not only being the support for budget control, but providing clear provisions for budget making. The lack of clarity in the budgeting systems is one of the reasons for the inaccurate budgeting. Therefore, it is necessary to set out the relevant regulations to clarify the budget management agencies, decision-making agencies and implementing agencies, to construct all-round mechanism of decision-making, supervision, restraint and consultation.

\subsection{Technology}

With the development of information technology, universities can make better use of technical means to reduce information asymmetry of budget making, to standardize the budget making. On the one hand, budgeting requires a reasonable method of calculation, regarding budget performance indicators as standards for budgeting. Therefore, the university in the management can try to combine the performance budget and zero-based budget as a comprehensive methodology. On the other hand, the current information management system of Chinese universities still need to be improved, as its function on budget management is limited. Therefore, universities need to increase the investment of information technology, constructing modern information management system 
with better function of preservation, transmission and analysis for data.

\subsection{Behaviours}

Budgeting is a process of interaction between superiors and subordinates. In the course of interaction, individual psychology will have an impact on their behaviours. So, the current improvement of budget making is how to achieve the aims by the way to change the individual's awareness. In the interaction between the upper and lower levels, the leadership as the owner of the power can be said to be the mainstay in the budgeting. Then the leadership's more attention can increase the whole departments' budget participation. In addition, employees have responsibility to communicate on the budget with each other. Because increasing budget participation also requires effective delivery of information, with the complete communication between agencies or departments. The mutual understanding, between the responsible institutions and the business departments, could improve the authenticity of the budget information, and then universities have access to make budget preparation more scientific and complete the budget making timely.

\section{Conclusion}

Under the guidance of the government, the budgeting of universities has formed basic model, however, the existence of the model is still flawed. Unreasonable preparation of the budget easily leads to budget loosening and other issues. There are several reasons why these problems arise. First of all, the relevant departments of budget management in universities set unreasonably, where there is no more detailed division of responsibility, with the result of inadequate budget controlling and preparation work being concentrated in a few people. Secondly, the budget management of universities is technically unreasonable. Without the support of information technology, poor information flow appears, causing a poor impact on budgeting time and the budget preparation. Finally, the existence of these problems requires the attention of the leadership, who should lead the various levels to actively participate in the budget making.

\section{References}

[1] Dalton Rex. Bleak outlook for universities as state budget deficits bite. [J]. Nature, 2003,421 (6918).

[2] Gene M. Nordby. Making the University Budget System Work for You [J]. Journal of Management in Engineering, 1986, 2 (1).

[3] William F. Massy. A Dynamic Equilibrium Model for University Budget Planning [J]. Management Science, 1976, 23 (3).

[4] Liu Yongze, Tang Dapeng. On the internal control of administrative institutions of several issues [J]. Accounting Research, 2013, (01): 57-62 +96.

[5] Nie Lijie, Wang Junmei. About performance budgeting and the budget method of combining the zero-base budget system thinking [J]. Journal of central university of finance and economics, 2004, (12): 1-5.

[6] the Ministry of Finance budgeting task group on the budgeting model and the operating mechanism of the study [J]. Economic Research Reference, 2000, (27): 2-28. 